\title{
Protein delivery nanosystem of six-arm copolymer poly(E-caprolactone)-poly(ethylene glycol) for long-term sustained release
}

This article was published in the following Dove Press journal: International Journal of Nanomedicine

\author{
Jianwei Duan ${ }^{1, *}$ \\ Chao Liu',* \\ Xiaoyu Liang' \\ Xuanling $\mathrm{Li}^{\prime}$ \\ Youlu Chen' \\ Zuoguan Chen ${ }^{2}$ \\ Xiaoli Wang' \\ Deling Kong ${ }^{1,3}$ \\ Yongjun $\mathrm{Li}^{2}$ \\ Jing Yang'
}

'Tianjin Key Laboratory of Biomaterial Research, Institute of Biomedical Engineering, Chinese Academy of Medical Science and Peking Union Medical College, Tianjin, China;

${ }^{2}$ Department of Vascular Surgery, Beijing Hospital, National Center of Gerontology, Chinese Academy of Medical Science and Peking Union Medical College, Beijing, China; ${ }^{3}$ Key Laboratory of Bioactive Materials, Ministry of Education, Nankai University, Tianjin, China

*These authors contributed equally to this work

\begin{abstract}
Background: To address the issue of delivery of proteins, a six-arm copolymer, six-arm poly ( $\varepsilon$-caprolactone)-poly(ethylene glycol) (6S-PCL-PEG), was synthesized by a simple two-step reaction. Thereafter, the application of 6S-PCL-PEG as a protein carrier was evaluated.
\end{abstract}

Materials and methods: A six-arm copolymer, six-arm poly( $\varepsilon$-caprolactone) (6S-PCL), was synthesized by ring-opening polymerization, with stannous octoate as a catalyst and inositol as an initiator. Then, poly(ethylene glycol) (PEG) was linked with 6S-PCL by oxalyl chloride to obtain 6S-PCL-PEG. Hydrogen-1 nuclear magnetic resonance spectrum, Fourier-transform infrared spectroscopy, and gel-permeation chromatography were conducted to identify the structure of 6S-PCL-PEG. The biocompatibility of the 6S-PCL-PEG was evaluated by a cell counting kit-8 assay. Polymeric nanoparticles (NPs) were prepared by a water-in-oil-in-water double emulsion $\left(\mathrm{W}_{1} / \mathrm{O} / \mathrm{W}_{2}\right)$ solvent evaporation method. The size distribution and zeta potential of NPs were determined by dynamic light scattering. Transmission electron microscopy was used to observe the morphology of NPs. Drug-loading capacity, encapsulation efficiency, and the release behavior of ovalbumin (OVA)-loading NPs were tested by the bicinchoninic acid assay kit. The stability and activity of OVA released from NPs were detected and the uptake of NPs was evaluated by NIH-3T3 cells.

Results: All results indicated the successful synthesis of amphiphilic copolymer 6S-PCL-PEG, which possessed excellent biocompatibility and could formulate NPs easily. High drug-loading capacity and encapsulation efficiency of protein NPs were observed. In vitro, OVA was released slowly and the bioactivity of OVA was maintained for over 28 days.

Conclusion: 6S-PCL-PEG NPs prepared in this study show promising potential for use as a protein carrier.

Keywords: six-arm PCL-PEG, copolymer synthesis, protein carrier, sustained release

\section{Introduction}

Compared with many conventional treatments, therapeutics of peptides and proteins possess noteworthy advantages such as high effectiveness, excellent specificity, and good activity. ${ }^{1}$ However, their clinical application has been limited by the protein-based drugs encountering several challenges, such as degradation by enzymes in the systemic circulation, poor bioavailability, and low cell permeability. ${ }^{2}$ Therefore, to address these issues, extensive research efforts have gone into finding and characterizing suitable protein delivery carriers. ${ }^{3-5}$ Among these, many excellent carrier biomaterials have been discovered, such as poly(lactic-co-glycolic acid) (PLGA), poly(caprolactone) (PCL), mesoporous silica, chitosan, cyclodextrin, and carbon nanotubes. ${ }^{6-11}$ However, the challenges of low cell permeability and short biological half-life remain. The short 
biological half-life of protein-based drugs causes a short action time of drugs and affect the therapeutic effects. ${ }^{12}$ Therefore, long-term sustained-release systems have emerged. Many researchers have put their efforts into this and various biodegradable protein delivery systems have been obtained. For example, Peng et al explored insulin-phospholipid complexloaded poly(hydroxybutyrate-co-hydroxyhexanoate) nanoparticles (NPs) as a sustained drug delivery system to increase the biological half-life of insulin. ${ }^{13}$ Xie et al used PLGA as a novel emulsifier to prepare hydrophilic protein-loaded solid lipid NPs to improve therapeutic efficiency. ${ }^{14}$ Besides, amphiphilic polymers have many advantages and have been studied widely as well. ${ }^{15-18}$

Amphiphilic polymers have many advantages, such as a long circulation duration, high biocompatibility, and augmented loading capacity. ${ }^{19-21}$ Poly(ethylene glycol) (PEG) has been widely used in this regard. Conjugation of PEG has exhibited significantly improved hydrophilicity as well as prolonged drug circulation period in vivo, features which are considered beneficial for NP-based delivery systems. $^{22-24}$ Therefore, various biodegradable amphiphilic block copolymers, such as poly(caprolactone)-poly(ethylene glycol) (PCL-PEG), poly(lactide)-poly(ethylene glycol) (PLA-PEG), and poly(lactide-glycolide)-poly(ethylene glycol) (PLGA-PEG) copolymers, have been synthesized and applied in drug delivery systems. Particularly noteworthy are star-shaped amphiphilic copolymers, which have attracted increasing attention because they exhibit many advantages over linear amphiphilic copolymers of the same molar mass, such as a smaller hydrodynamic diameter, lower solution viscosity, and higher stability. ${ }^{25-27}$ Moreover, several reports have demonstrated that star-shaped copolymers have other advantages in drug delivery compared with linear copolymers, such as prolonging sustained release and improving the drug-loading capacity. ${ }^{28-30}$

The overall aim of the present work was to develop a sustained-release star-shaped amphiphilic copolymer carrier [six-arm poly( $\varepsilon$-caprolactone)-poly(ethylene glycol) (6S-PCL-PEG)], which augments the encapsulation efficiency and the protein-loading capacity. Initial work in this study focused on the preparation of 6S-PCL-PEG by a two-step method which is simple and efficient. ${ }^{31}$ Thereafter, ovalbumin (OVA) was used as a model protein and a doubleemulsion solvent evaporation method was employed to prepare the NPs, followed by property analysis, in vitro stability, and release behavior studies of NPs. Further, the in vitro uptake of NPs by NIH-3T3 cells was performed to examine the potential of this formulation in delivering protein into living cells.

\section{Materials and methods Materials}

$\varepsilon$-Caprolactone, stannous octoate, OVA, and polyvinyl alcohol (PVA) $\left(M_{\mathrm{n}}=30,000-70,000\right)$ were purchased from SigmaAldrich (St Louis, MO, USA). PEG $\left(M_{\mathrm{n}}=4,000 \mathrm{~g} / \mathrm{mol}\right)$, inositol, and oxalyl chloride (chemically pure) were bought from GuangFu Fine Chemical Research Institute (Tianjin, China). Calcium hydride, dichloromethane $\left(\mathrm{CH}_{2} \mathrm{Cl}_{2}\right)$, methanol, and diethyl ether were procured from Tianjin Jiang Tian Chemical Technology Co. (Tianjin, China). Lipopolysaccharide (LPS), PBS, Tween 20, Roswell Park Memorial Institute (RPMI) 1640 (Hyclone), and fetal bovine serum (FBS) were supplied by Solarbio (Beijing, China). The MicroBCA ${ }^{\mathrm{TM}}$ protein assay kit was obtained from Thermo Fisher Scientific (Rockford, IL, USA). Anti-mouse enzyme-linked immunosorbent assay (ELISA) kits, tumor necrosis factor- $\alpha$ (TNF- $\alpha$ ), and IL-6 were purchased from eBioscience (San Diego, CA, USA). $\varepsilon$-Caprolactone and dichloromethane were distilled with calcium hydride, while other reagents were used as received.

NIH-3T3 and RAW-264.7 cell lines were purchased from the Institute of Basic Medical Sciences, Chinese Academy of Medical Sciences (Beijing, China).

Six-week-old female C57BL/6 mice were bought from the Academy of Military Medical Sciences (Beijing, China). The Administrative Committee on Animal Research in the Institute of Biomedical Engineering, Chinese Academy of Medical Sciences, approved all the protocols for animal experiments. All the animal experiments were performed in compliance with the Guiding Principles for the Care and Use of Laboratory Animals, Peking Union Medical College, China.

\section{Synthesis of 6S-PCL}

Classical ring-opening polymerization was employed to produce 6S-PCL. In brief, $195.7 \mathrm{mg}$ inositol $(1.095 \mathrm{mmol}$; Aladdin, Shanghai, China) was charged into a two-neck round-bottom polymeric flask. Then, $23.38 \mathrm{~mL} \varepsilon$-caprolactone (219 mmol) and $1.21 \mathrm{~mL}$ stannous octoate $(0.0365 \mathrm{mmol})$ were added into the flask. This was followed by degassing for $10 \mathrm{~min}$ and argon-filling for $1 \mathrm{~min}$ three times to remove the oxygen in the flask. Thereafter, a vacuum was required and the reaction was maintained at $180^{\circ} \mathrm{C}$ for $48 \mathrm{~h}$. The resulting product was cooled to ambient temperature and dissolved in $\mathrm{CH}_{2} \mathrm{Cl}_{2}$, then purified by precipitation with ice methanol three times. Finally, 6S-PCL polymer was obtained after filtering and drying in a vacuum for $24 \mathrm{~h}$.

\section{Synthesis of 6S-PCL-PEG}

First, oxalyl chloride (1.50 g, $11.84 \mathrm{mmol})$ was dissolved in $10 \mathrm{~mL}$ anhydrous $\mathrm{CH}_{2} \mathrm{Cl}_{2}$ in a flask. Then, $15 \mathrm{~mL}$ anhydrous 
$\mathrm{CH}_{2} \mathrm{Cl}_{2}$ solution containing PEG (3.16 g, $\left.0.789 \mathrm{mmol}\right)$ and $0.240 \mathrm{~g}$ triethylamine $(2.367 \mathrm{mmol})$ were added dropwise into the flask under stirring for $3 \mathrm{~h}$ at $4^{\circ} \mathrm{C}$. Thereafter, the reaction solution was reevaporated and redissolved in $\mathrm{CH}_{2} \mathrm{Cl}_{2}$ three times. The final residue and triethylamine $(0.053 \mathrm{~g}$, $0.526 \mathrm{mmol}$ ) were co-dissolved in $20 \mathrm{~mL}$ dried $\mathrm{CH}_{2} \mathrm{CI}_{2}$. The anhydrous $\mathrm{CH}_{2} \mathrm{Cl}_{2}$ solution containing 6S-PCL (1 g, $0.044 \mathrm{mmol}$ ) was added into the above solution dropwise under stirring at ambient temperature in a nitrogen atmosphere for $48 \mathrm{~h}$. After washing three times in $1 \mathrm{M} \mathrm{HCl}$ and saturated $\mathrm{NaCl}$ solution, the solution was dried with anhydrous $\mathrm{MgSO}_{4}$. After filtration, the filtered solution was precipitated in cold diethyl ether three times and washed in cold methanol to remove unreacted PEG. The resulting product was obtained after drying at $40^{\circ} \mathrm{C}$ in a vacuum for $24 \mathrm{~h}$ until achieving a constant weight.

Hydrogen-1 nuclear magnetic resonance ( $\left.{ }^{1} \mathrm{H}-\mathrm{NMR}\right)$ spectroscopy measurements were performed using a $400 \mathrm{MHz}$ spectrometer (Varian, Palo Alto, CA, USA) with $\mathrm{CDCl}_{3}$ as the solvent and tetramethylsilane as the internal reference, with a chemical shift of 0 ppm. ${ }^{31}$ A Nicolet Nexus 470-ESP Fouriertransform infrared (FTIR) spectrometer (Thermo Fisher Scientific, Waltham, MA, USA) was employed to analyze the main functional groups. The molecular weight of the copolymer was investigated by gel-permeation chromatography (GPC) with polymethyl methacrylate (PMMA) as the standard using a Hitachi L-2490 differential refraction detector and two Agilent PL gel particle columns $(7.5 \times 300 \mathrm{~mm}, 10 \mathrm{~mm})$.

\section{Preparation of NPs}

NPs were prepared by a water-in-oil-in-water double emulsion $\left(\mathrm{W}_{1} / \mathrm{O} / \mathrm{W}_{2}\right)$ solvent evaporation method. ${ }^{32} \mathrm{OVA}$, as a model protein, was encapsulated into the NPs. In brief, the aqueous solution containing $15 \mathrm{mg}$ OVA was added to $25 \mathrm{mg} / \mathrm{mL}$ copolymer $\mathrm{CH}_{2} \mathrm{CI}_{2}$ solution to form a water-in-oil emulsion at 35\% amplitude with a microtip probe sonicator (VCX-130-PB; Sonics \& Materials, Newtown, CT, USA). Then, the primary emulsion was added into another aqueous solution containing $0.5 \%(\mathrm{w} / \mathrm{v})$ PVA at $30 \%$ amplitude. Thereafter, the multiple emulsion was stirred in a fume hood to volatilize the organic solvent. Finally, the NPs were washed three times by centrifugation at 23,000 rpm for $30 \mathrm{~min}$, then freeze-dried and stored at $4^{\circ} \mathrm{C}$. Blank 6S-PCLPEG NPs were produced in a similar manner by adding nothing to the first aqueous solution.

\section{In vitro biocompatibility assay of NPs}

A cell counting kit-8 (CCK-8) assay (Dojindo, Kumamoto, Japan) was used to detect the biocompatibility of blank NPs with NIH-3T3 cells and RAW-264.7 cells. In brief, cells were seeded in 96 -well culture plate $\left(5 \times 10^{3}\right.$ cells/well $)$ using RPMI 1640 medium for $24 \mathrm{~h}$. Then, cells were treated with blank NPs at different concentrations $(12.5,25,50$, and $100 \mu \mathrm{g} / \mathrm{mL})$ for another $24 \mathrm{~h}$. Thereafter, the medium was removed and $200 \mu \mathrm{L}$ mixture medium (RPMI 1640 with $10 \%$ FBS/CCK-8, $9 / 1, \mathrm{v} / \mathrm{v}$ ) was added to each well and incubated for $2 \mathrm{~h}$. The absorbance $(\mathrm{AB})$ at $450 \mathrm{~nm}$ was detected with a Varioskan Flash Microplate Reader (Thermo Fisher Scientific, Waltham, MA, USA). The relative cell viability was calculated as follows and the results are represented as mean $\mathrm{SD}(\mathrm{n}=3)$.

$$
\text { Cell viability }(\%)=\frac{\mathrm{AB}_{\text {sample }}-\mathrm{AB}_{\text {blank }}}{\mathrm{AB}_{\text {control }}-\mathrm{AB}_{\text {blank }}} \times 100 \%
$$

To evaluate the biocompatibility of the blank NPs further, RAW-264.7 cells were co-cultured with blank NPs and the cytokine secretion of RAW-264.7 cells was measured by ELISA. In brief, RAW-264.7 cells were cultivated with RPMI 1640 containing $10 \%$ FBS and $1 \%$ penicillin streptomycin at $37^{\circ} \mathrm{C}$ in a $5 \%(\mathrm{v} / \mathrm{v})$ carbon dioxide atmosphere. Then, RAW264.7 cells were seeded into 24 -well plates with a density of $5 \times 10^{5}$ cells/well and incubated for $24 \mathrm{~h}$. Thereafter, cells were treated with different concentrations of blank NPs $(12.5,25$, and $50 \mu \mathrm{g} / \mathrm{mL}$ ) and incubated for another $24 \mathrm{~h}$. The cytokines IL-6 and TNF- $\alpha$ in supernatants were analyzed. LPS was used as a positive control. ${ }^{33}$

\section{Characterization of NPs}

Size, polydispersity, zeta potential, morphology, and stability of NPs

The size and zeta potential of the OVA-loaded NPs in aqueous solution were measured by dynamic light scattering (DLS) using a Zetasizer Nano ZS (Malvern Instruments, Malvern, UK). Each sample was analyzed in triplicate. The morphology of the NPs was observed by transmission electron microscopy (TEM) (Tianjin Research Center of Basic Medical Science, Tianjin, China). A drop of freshly prepared NP suspension was deposited on to a copper grid. Then, the grid was dried at room temperature overnight before being examined by TEM. To evaluate the stability of NPs, changes in particle size and size distribution were closely monitored every 15 days for 1 month.

\section{Encapsulation efficiency and loading capacity}

The encapsulation efficiency (EE) and protein-loading capacity (LC) of NPs were detected by a bicinchoninic acid (BCA) assay kit (Beyotime, Shanghai, China). In brief, OVA-loaded NPs were dissolved in $1 \mathrm{M} \mathrm{NaOH}$ and incubated in a shaker 
at $37^{\circ} \mathrm{C}$ for $3 \mathrm{~h}$. Then, an equal volume of $1 \mathrm{M} \mathrm{HCl}$ was added to neutralize the $\mathrm{NaOH}$. OVA in the supernatant was determined using the BCA assay kit. The EE and LC were calculated by the following equations. The determinations were carried out in triplicate and the results are expressed as mean $\pm \mathrm{SD}(\mathrm{n}=3)$.

$$
\begin{gathered}
\mathrm{EE}=\frac{\mathrm{OVA}_{\text {total }}-\mathrm{OVA}_{\text {supernatant }}}{\mathrm{OVA}_{\text {total }}} \times 100 \% \\
\mathrm{LC}=\frac{\text { Loaded OVA }}{\text { Total mass of NPs }} \times 100 \%
\end{gathered}
$$

\section{In vitro OVA release}

OVA was used as a model protein for determining protein release behavior from 6S-PCL-PEG NPs in vitro. The detection of OVA released from 6S-PCL-PEG NPs was carried out in PBS (pH 7.4) at $37^{\circ} \mathrm{C}$. First, $20 \mathrm{mg}$ of OVA-loaded NPs was suspended in $4 \mathrm{~mL}$ PBS ( $\mathrm{pH} 7.4$ ) and shaken at $150 \mathrm{rpm}$ at $37^{\circ} \mathrm{C}$ for 28 days. The amount of released OVA was measured at set time points. After centrifugation, $2 \mathrm{~mL}$ of supernatant was collected and an equal volume of PBS was added. Total protein in the supernatant samples was measured with the BCA assay kit according to the manufacturer's instructions. Absorbance at $562 \mathrm{~nm}$ was measured using a microplate reader (Varioskan LUX multimode reader; Thermo Fisher Scientific). Protein concentrations were calculated according to standard curves.

\section{Stability and activity of OVA released from NPs}

Secondary structures and molecular weight were used to evaluate the stability of protein before and after the preparation of NPs. ${ }^{34}$ The changes in secondary structures of OVA encapsulated in NPs were monitored by far-ultraviolet circular dichroism (CD). All results of CD spectra were collected on a J-815 spectrometer (JASCO, Tokyo, Japan) with a $1 \mathrm{~mm}$ quartz cell. The background PBS solution was subtracted from each protein spectrum and native OVA as the control. A minimum of three protein spectra were collected per sample and averaged. Sodium dodecyl sulfate-polyacrylamide gel electrophoresis (SDS-PAGE) was employed to qualitatively identify the integrity of OVA which was encapsulated into 6S-PCL-PEG NPs.

Bioactivity is of importance for proteins. In this study, therefore, splenocyte proliferation was used to evaluate the OVA bioactivity. ${ }^{35}$ In brief, 6-week-old female C57BL/6 mice (five mice/group) were immunized with naked OVA or OVA released from NPs (20 $\mu \mathrm{g}$ OVA/mouse) by subcutaneous injection three times at 2 week intervals. Splenocytes were isolated 7 days after the last immunization and splenocytes $\left(1 \times 10^{6}\right.$ cells $\left./ \mathrm{mL}\right)$ were restimulated with soluble OVA $(20 \mu \mathrm{g} / \mathrm{mL})$ in a 96 -well plate at $37^{\circ} \mathrm{C}$ for $72 \mathrm{~h}$. Following this, splenocyte proliferation was detected by MTT at $570 \mathrm{~nm}$ using a Varioskan Flash Microplate Reader (Thermo Fisher Scientific).

\section{In vitro cellular uptake studies}

NIH-3T3 cells $\left(5 \times 10^{4}\right.$ cells $\left./ \mathrm{mL}\right)$ were seeded in a confocal dish for $24 \mathrm{~h}$ then cultured with fluorescein isothiocyanate (FITC)-conjugated OVA (OVA-FITC) or OVA-FITC encapsulated NPs (OVA-FITC NPs) at $37^{\circ} \mathrm{C}$ for $4 \mathrm{~h}$. Thereafter, the cell nuclei were stained with 4',6-diamidino-2-phenylindole (DAPI) (Sigma, St Louis, MO, USA) for 5 min. Florescent images were recorded by confocal laser scanning microscopy (CLSM 410; Zeiss, Jena, Germany).

For quantitative cellular uptake analysis, NIH-3T3 cells were cultured with OVA-FITC and OVA-FITC NPs at $37^{\circ} \mathrm{C}$ for $4 \mathrm{~h}$ and then washed. The uptake efficiency of NPs by NIH-3T3 cells was expressed as OVA-FITC-positive cells and mean fluorescence intensity, which were determined by a BD AccuriTM C6 flow cytometer (BD Biosciences, San Jose, CA, USA).

\section{Results and discussion Characterization of copolymer}

A schematic illustration of the copolymer is depicted in Figure 1. First, inositol as the initiator and stannous octoate as the catalyst were used to synthesize $6 \mathrm{~S}$-PCL by ringopening polymerization. Then, 6S-PCL was linked to PEG by an acylation reaction using oxalyl chloride to obtain 6S-PCL-PEG. Compared with the traditional synthesis method using dicyclohexylcarbodiimide (DCC) and $\mathrm{N}$-hydroxysuccinimide (NHS), this synthetic method is simple and convenient. ${ }^{30,31,36}$

${ }^{1} \mathrm{H}-\mathrm{NMR}$ was used to confirm the chemical structure of 6S-PCL and 6S-PCL-PEG. The resonance peaks a $(\delta=4.05)$, $\mathrm{b}(\delta=1.66), \mathrm{c}(\delta=1.41)$, and d $(\delta=2.31)$ were assigned to the protons of $\mathrm{CH}_{2}$ in the PCL (Figure 2A). In the ${ }^{1} \mathrm{H}-\mathrm{NMR}$ spectra of 6S-PCL-PEG, the high-intensity peak at $3.62 \mathrm{ppm}$ (Figure $2 \mathrm{~B}$ ) belongs to the protons in $\mathrm{CH}_{2}$ of $\mathrm{PEG}$, whereas the other peaks assigned to 6S-PCL remained. All these results indicate the existence of $\mathrm{PEG}$, which proves that 6S-PCL-PEG was synthesized successfully. We also calculated the molecular weight of the end product by comparing the integration areas of NMR spectra from PCL and PEG blocks (Figure S1). The total molar ratio between caprolactone and ethylene glycol was about 276:552. Therefore, the 


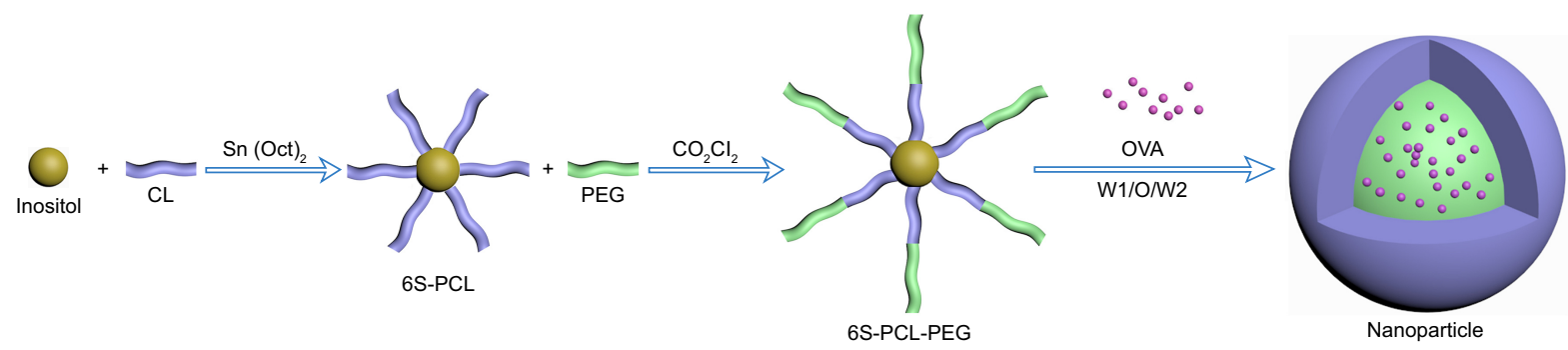

Figure I Schematic illustration of the synthesis of 6S-PCL-PEG. The hydrophilic model drug OVA was incorporated into the hydrophilic core with a WI/O/W2 solvent evaporation method.

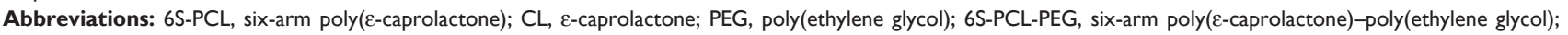
OVA, ovalbumin; WI/O/W2, water-in-oil-in-water double emulsion.

molecular weight of the end product calculated by ${ }^{1} \mathrm{H}-\mathrm{NMR}$ was about 56,000 .

FTIR spectrometry was employed to identify the chemical structure of the copolymer. As shown in Figure 2C, the peaks of $2,946 \mathrm{~cm}^{-1}$ and $2,867 \mathrm{~cm}^{-1}$ were attribute to the saturated $-\mathrm{CH}$ bond and the peak at $1,725 \mathrm{~cm}^{-1}$ was a carbonyl group. However, after PEG modification, the absorbance peaks $2,946 \mathrm{~cm}^{-1}$ and $2,867 \mathrm{~cm}^{-1}$ of the $-\mathrm{CH}$ bond in

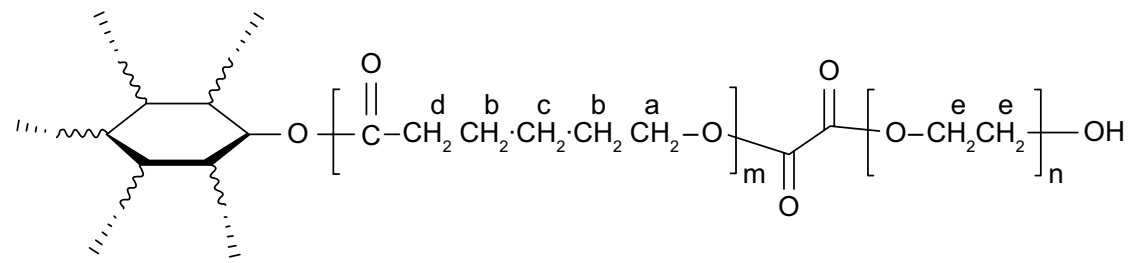

A

6S-PCL

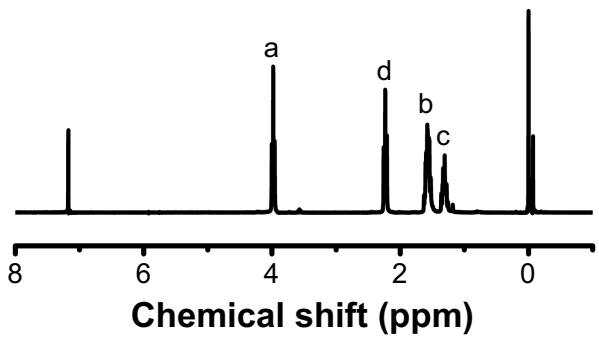

C

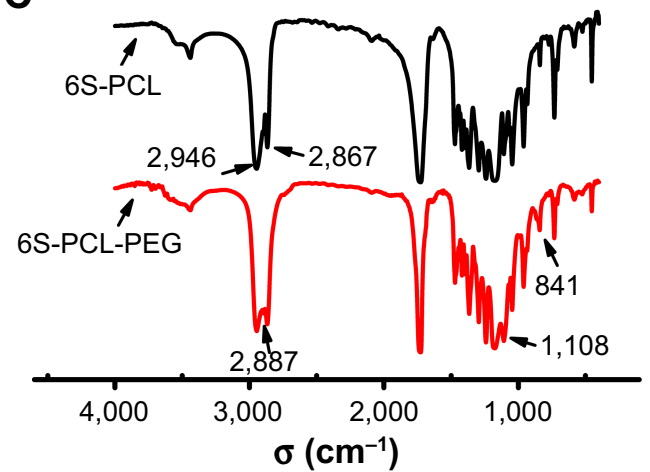

B

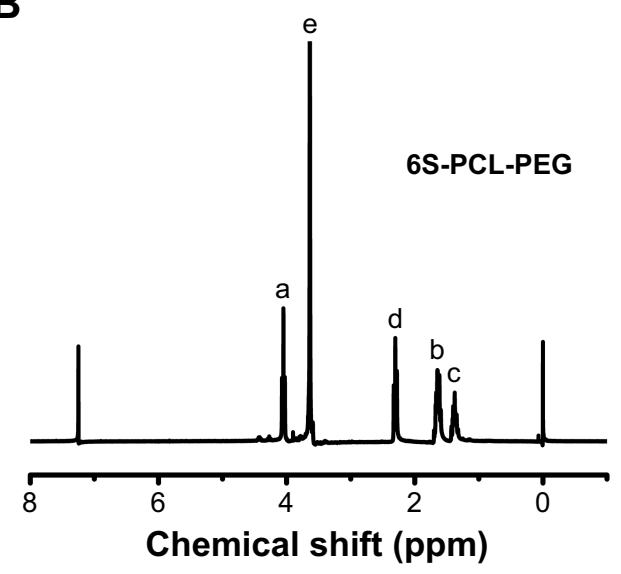

D

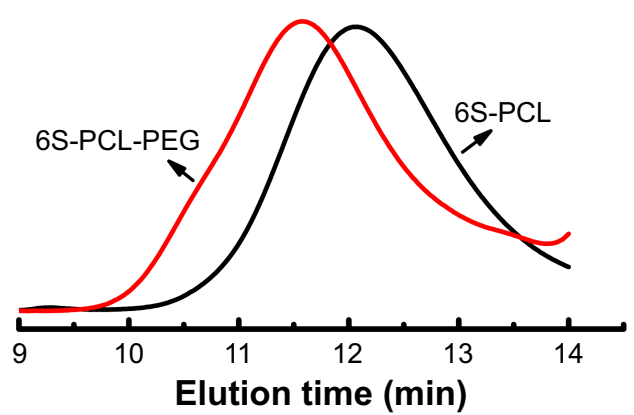

Figure 2 Synthesis and characterization of 6S-PCL and 6S-PCL-PEG. (A) 'H-NMR spectrum of 6S-PCL. (B) 'H-NMR spectrum of 6S-PCL-PEG. (C) FTIR spectrometry of 6S-PCL and 6S-PCL-PEG. (D) Molecular weights of 6S-PCL and 6S-PCL-PEG investigated by GPC.

Notes: a, $(\delta=4.05 \mathrm{ppm})$; b, $(\delta=1.66 \mathrm{ppm}) ; \mathrm{c},(\delta=\mathrm{I} .4 \mathrm{I} \mathrm{ppm})$; and $\mathrm{d},(\delta=2.3 \mathrm{I} \mathrm{ppm})$. Compared with the $6 \mathrm{~S}-\mathrm{PCL}$ spectrum, the high intensity of peak e $\left(\delta=3.62 \mathrm{ppm},-\mathrm{CH}_{2}\right.$ in PEG segments) in the 6S-PCL-PEG spectrum indicated the existence of PEG.

Abbreviations: 6S-PCL, six-arm poly( $\varepsilon$-caprolactone); 6S-PCL-PEG, six-arm poly( $\varepsilon$-caprolactone)-poly(ethylene glycol); 'H-NMR, hydrogen-I nuclear magnetic resonance; FTIR, Fourier-transform infrared; GPC, gel-permeation chromatography. 
PCL were buried in the peak $2,887 \mathrm{~cm}^{-1}$ of $-\mathrm{CH}_{2}$ groups in PEG, and the new peaks of $1,108 \mathrm{~cm}^{-1}$ and $841 \mathrm{~cm}^{-1}$ of single-bond $\mathrm{C}-\mathrm{O}$ were characteristic of $\mathrm{PEG}$. All emerging peaks of 6S-PCL-PEG proved the existence of the PEG chain in the product.

The result of GPC is shown in Figure 2D. Compared to $6 \mathrm{~S}-\mathrm{PCL}$, the reduction in the retention time in the GPC curve of 6S-PCL-PEG indicated an increase in molecular weight, demonstrating the attachment of PEG to 6S-PCL. The molecular weight of 6S-PCL was 38,211 and that of 6S-PCLPEG was 59,953 L. The polydispersity of the copolymer was narrow (1.495 for 6S-PCL and 1.523 for 6S-PCL-PEG). The molecular weight of 6S-PCL-PEG measured by GPC was closed to the result calculated by ${ }^{1} \mathrm{H}-\mathrm{NMR}$, which also indicates that $6 \mathrm{~S}-\mathrm{PCL}-\mathrm{PEG}$ was synthesized successfully.

\section{Biocompatibility of copolymer NPs}

Drug carriers should not release toxic products or produce adverse reactions, and this can be evaluated through in vitro cytotoxicity tests. The cytotoxicity of blank NPs was assessed with a CCK-8 assay. NIH-3T3 cells and RAW-264.7 cells were incubated for $24 \mathrm{~h}$ with blank NPs, with concentrations ranging from $12.5 \mu \mathrm{g} / \mathrm{mL}$ to $100 \mu \mathrm{g} / \mathrm{mL}$. Figure $3 \mathrm{~A}$ shows that the blank 6S-PCL-PEG NPs did not exhibit obvious cytotoxicity compared with the control group, indicating the commendable biocompatibility of blank NPs.

RAW-264.7 cells were also employed to evaluate the biocompatibility of copolymer NPs by detecting typical inflammatory cytokines such as IL-6 and TNF- $\alpha .{ }^{37}$ We measured the cytokines (IL-6 and TNF- $\alpha$ ) released in culture supernatant after $24 \mathrm{~h}$ incubation with blank NPs. Figure 3B shows that there was no significant difference in cytokine secretion between the NP groups and the negative control group. However, much higher levels of cytokines were released in the positive group (LPS), which proved that the blank NPs would not elicit inflammatory responses in RAW264.7 cells. This result was consistent with the above results, implying that the NPs have good biocompatibility.

\section{Characterization of NPs}

The NPs prepared by a double-emulsion $\left(\mathrm{W}_{1} / \mathrm{O} / \mathrm{W}_{2}\right)$ solvent evaporation method exhibited suitable particle size and negative charge. The particle size of 6S-PCL NPs was $190.7 \pm 1.665 \mathrm{~nm}$ and the polydispersity index (PDI) was $0.164 \pm 0.010$ (Figure S2). As shown in Figure 4A, OVAloaded NPs had an average diameter of $233.4 \pm 0.565 \mathrm{~nm}$, which is in the size range suitable for reducing uptake by the reticuloendothelial system and prolonging the circulation time in the blood. ${ }^{38-40}$ The 6S-PCL-PEG NPs would not easily be taken up by macrophages of the mononuclear-phagocyte system because macrophages readily phagocytose foreign matter in the range of $0.5-3 \mu \mathrm{m} .{ }^{41,42}$ Besides, the surface-grafted, flexible, and hydrophilic chains of PEG form conformational clouds, which also prevent protein (opsonin) adsorption to NPs and hence avoid capture by the mononuclear phagocyte system, ${ }^{43,44}$ which indicates that the NPs could have a long circulation period. The slightly negative charge of OVAloaded 6S-PCL-PEG NPs $(-10.4 \pm 0.9 \mathrm{mV})$ may decrease the undesirable clearance by the reticuloendothelial system, such as the liver, improving blood compatibility. ${ }^{45}$ PEGylation of NPs could also decrease protein adsorption in the circulation, which would also benefit the circulation duration of NPs. ${ }^{46}$
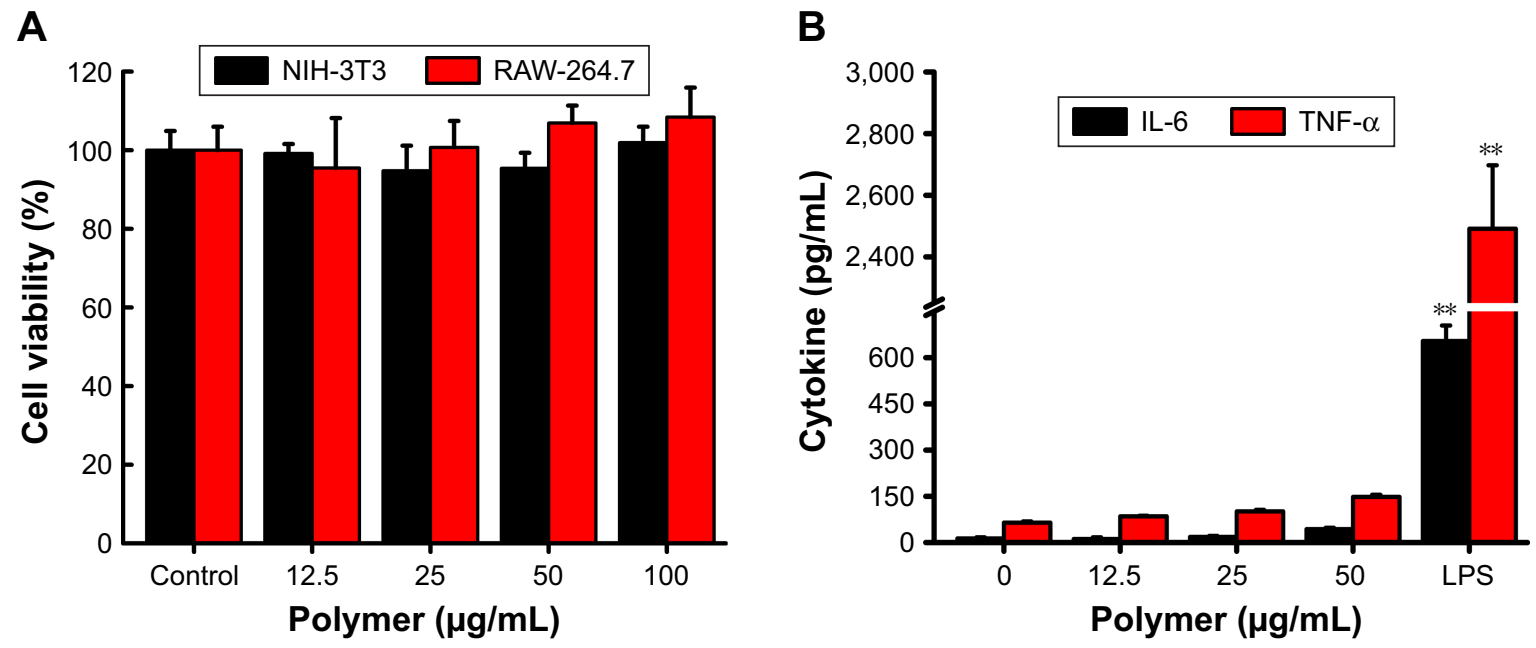

Figure 3 Biocompatibility of 6S-PCL-PEG NPs. (A) NIH-3T3 and RAW-264.7 cell viability after co-culture with NPs for 24 h. (B) Cytokine release of RAW-264.7 cells after co-culture with NPs for $24 \mathrm{~h}$. Bars are mean $\pm S D(n=3)$. The statistical significance of differences were analyzed using Student's $t$-test: ** $p<0.0$ I.

Abbreviations: 6S-PCL-PEG, six-arm poly( $\varepsilon$-caprolactone)-poly(ethylene glycol); NPs, nanoparticles; TNF- $\alpha$, tumor necrosis factor- $\alpha$. 
A

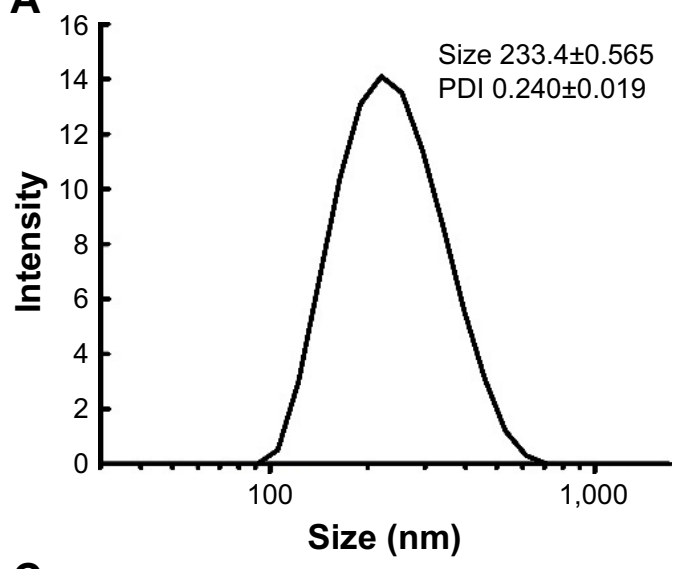

C

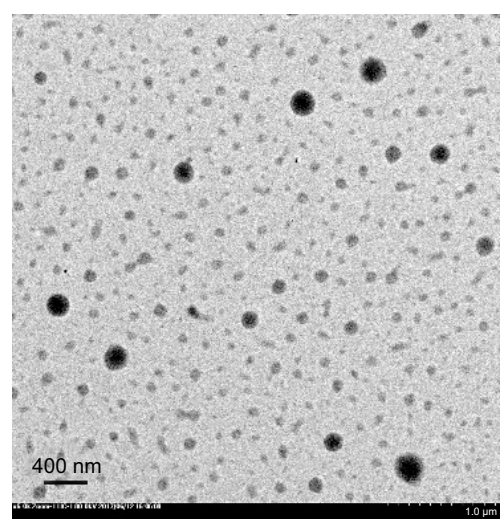

B

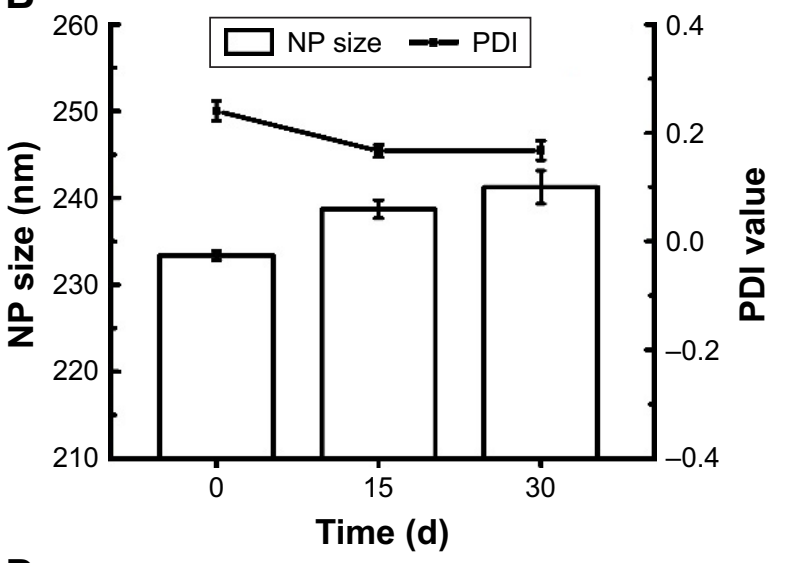

D

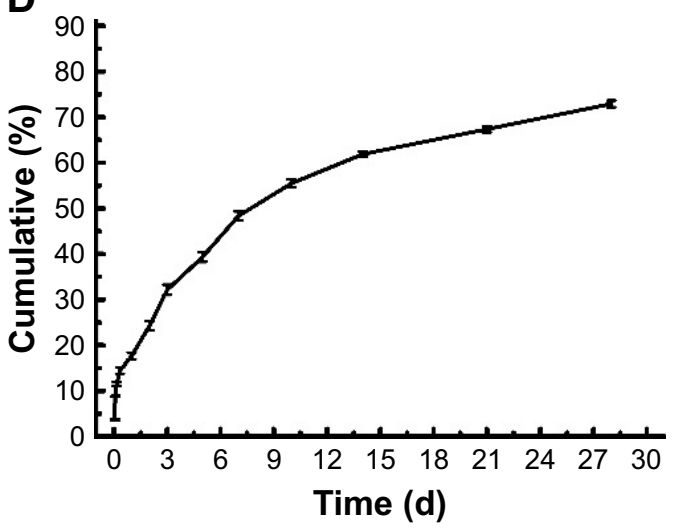

Figure 4 Characterization of 6S-PCL-PEG NPs in vitro. (A) Dynamic light scattering of 6S-PCL-PEG NPs. (B) The physical stability of 6S-PCL-PEG NPs in PBS was assessed by the change in NP size and PDI for 30 days. (C) TEM image of normal 6S-PCL-PEG NPs. Magnification is 5,000×. (D) OVA cumulative release from 6S-PCL-PEG NPs which were incubated in PBS (0.0I M, pH 7.4) for 28 days; the protein content was determined by a BCA assay. Bars are mean \pm SD $(n=3)$.

Abbreviations: 6S-PCL-PEG, six-arm poly(E-caprolactone)-poly(ethylene glycol); NPs, nanoparticles; PDI, polydispersity index; TEM, transmission electron microscopy; OVA, ovalbumin; BCA, bicinchoninic acid.

Stability is the "holy grail" for an excellent drug carrier. In this study, size change over 1 month was measured to evaluate the stability of NPs. ${ }^{47}$ As shown in Figure 4B, there were no obvious size changes during 1 month at $4{ }^{\circ} \mathrm{C}$, indicating that the NPs have great stability.

The morphology of OVA-loaded NPs was observed by TEM. TEM images clearly showed NPs with a spherical shape and separated from each other (Figure 4C). Their diameter was consistent with the results of DLS. We further measured the protein EE and LC of 6S-PCL-PEG NPs. Significant increases in EE $(85.8 \% \pm 0.7 \%)$ and LC $(28.5 \% \pm 1.3 \%)$ can be ascribed to the PEGylation. ${ }^{22}$

\section{In vitro release of OVA-loaded NPs}

In vitro release kinetics of OVA-loaded NPs in PBS (pH 7.4) during 28 days are shown in Figure 4D. The release curve of OVA from the 6S-PCL-PEG NPs exhibited a burst on the first day (which was less than $15 \%$ of the loaded OVA); however, a sustained-release profile was showed over 28 days and the cumulative release amount was about $70 \%$. The fast release of OVA in the initial stage could be attributed to the release of OVA on the surface layers of the NPs. ${ }^{48}$ The existence of poly( $\varepsilon$-caprolactone) and the structure of 6S-PCL-PEG copolymer in aqueous solution could form a more effective conformational cloud, which plays an important role in the sustained drug release..$^{25,27,49,50}$ The time of sustainable protein release in this study was approximately 1 month, which was longer than in other reports. ${ }^{8,51,52}$ The reason for this could be that PVA increases the viscosity of the external water phase and results in increased difficulty for the OVA aqueous solution to diffuse out. ${ }^{53}$ Overall, the NPs were effective protein delivery carriers, with suitable size, loading capacity, stability, and sustained-release properties.

\section{Stability and activity of OVA released from NPs}

Far-ultraviolet CD (200-250 nm) was used to monitor the secondary structure of protein encapsulated into NPs. 
A

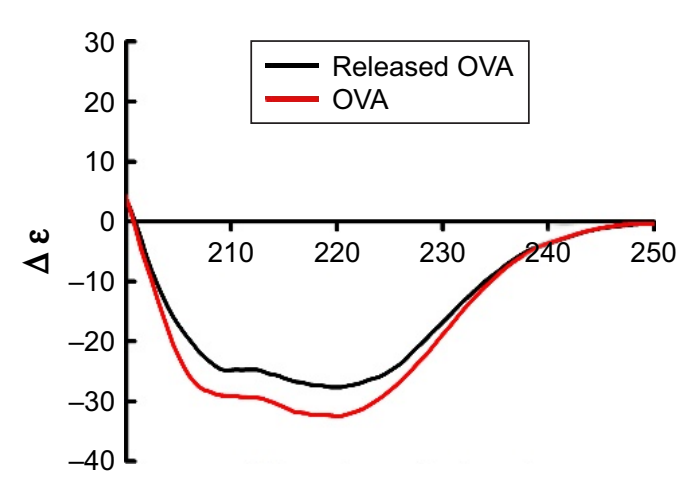

Wavelength $(\mathrm{nm})$
B

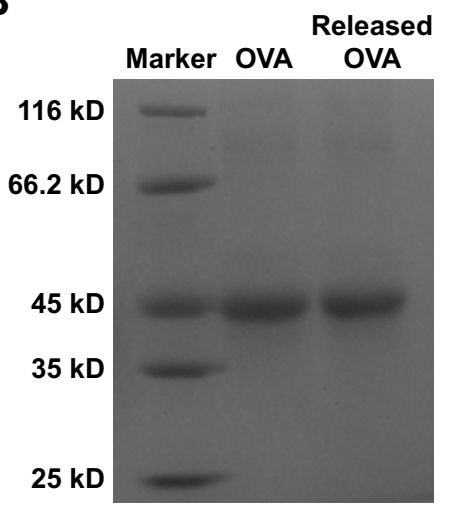

C

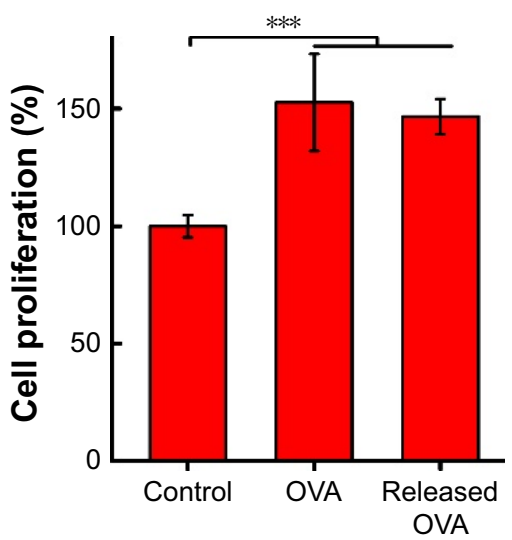

Figure 5 Secondary structure and molecular weight of OVA encapsulated into 6S-PCL-PEG NPs. (A) CD spectra of OVA. (B) Electrophoretogram of OVA. (C) Proliferation of splenocytes stimulated by OVA. Released OVA means the OVA released from NPs. Bars are mean $\pm S D(n=5)$. The statistical significance of differences were analyzed using Student's t-test: $* * * p<0.001$.

Abbreviations: OVA, ovalbumin; 6S-PCL-PEG, six-arm poly(E-caprolactone)-poly(ethylene glycol); CD, circular dichroism; NPs, nanoparticles.

As shown in Figure 5A, the CD spectra of native OVA and the OVA released from 6S-PCL-PEG NPs were similar and each spectrum had two minima, at $208 \mathrm{~nm}$ and $222 \mathrm{~nm}$, which indicated that OVA did not undergo any conformational changes during preparation and release from NPs. ${ }^{54}$ Figure $5 \mathrm{~B}$ shows that the molecular weight of OVA released from NPs was the same as with native OVA, which was consistent with the CD spectra results. The bioactivity of OVA released from NPs was examined by the MTT assay. The results in Figure 5C show that there was no significant difference in splenocyte proliferation between OVA and the OVA released from NPs, implying that the released OVA maintained its bioactivity.

\section{Cellular uptake of OVA-loaded NPs}

The cellular uptake efficiency of drug-loaded NPs affects the therapeutic effects. ${ }^{50}$ Therefore, the cellular uptake efficiency of drug-loaded NPs was detected using NIH-3T3 cells as a model. Figure 6A shows the results of CLSM after $4 \mathrm{~h}$ incubation in NIH-3T3 cells with the pristine OVA. The 6S-PCL NPs and the 6S-PCL-PEG NPs had the same equivalent OVA concentration; however, the green fluorescence in NIH-3T3 cells treated with 6S-PCLPEG NPs was significantly stronger than that in 6S-PCL NPs and native OVA, which indicated that 6S-PCL-PEG NPs showed enhanced cellular uptake compared with pristine OVA.

The cellular uptake of NPs was further investigated by C6 flow cytometry. Figure 6B and C shows the NIH-3T3 cellular uptake efficiency of the NPs compared with the native OVA after incubation for $4 \mathrm{~h}$. The same equivalent OVA concentration in the culture medium was applied in the experiment. It is evident from Figure 6B that more 6S-PCL-PEG NPs were taken up by NIH-3T3 cells after $4 \mathrm{~h}$ incubation compared with the 6S-PCL NPs (3.4-fold) and pristine OVA-FITC (25.7-fold). The representative flow plot is presented in Figure S3. A significant increase in the total fluorescence intensity of 6S-PCL-PEG was observed compared with soluble OVA and 6S-PCL NPs (Figure 6C). The mean fluorescence intensity plot is presented in Figure S4. These data confirm the enhanced cellular uptake by NP formulations, which is consistent with the results obtained from CLSM.

All the results showed that 6S-PCL-PEG NPs have distinct properties as protein carriers, such as outstanding stability, high loading capability, and excellent biocompatibility, and enhance the cellular uptake to improve the effects of the protein.

\section{Conclusion}

In this study, the copolymer 6S-PCL-PEG, with excellent biocompatibility, was successfully synthesized in two steps: ring-opening polymerization then esterification by oxalyl chloride. After modification by PEG, 6S-PCL-PEG NPs had higher encapsulation efficiency and drug-loading capacity. Compared with 6S-PCL NPs and naked OVA, the uptake of 6S-PCL-PEG NPs by NIH-3T3 cells was significantly increased. In summary, a polymeric protein vehicle, 6S-PCL-PEG NPs, with robust efficacy in the delivery of proteins into living cells, was prepared. NPs have great 
A
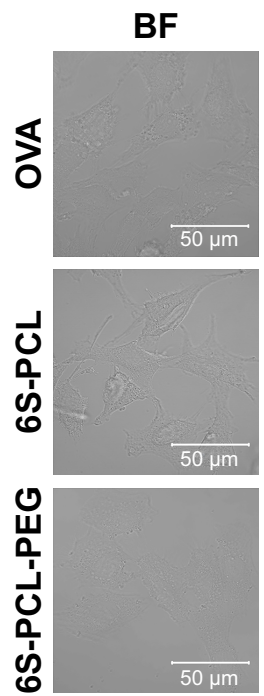

DAPI
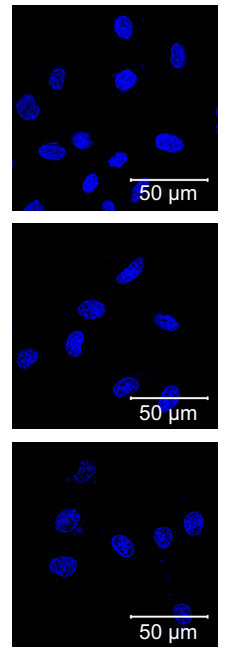
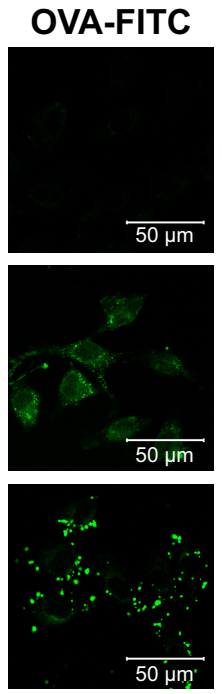
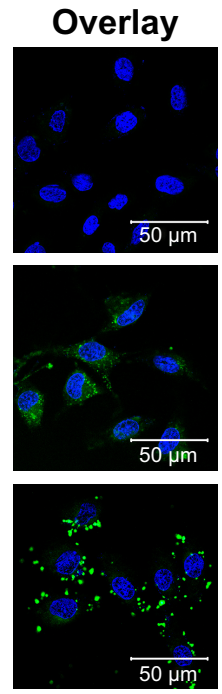

B
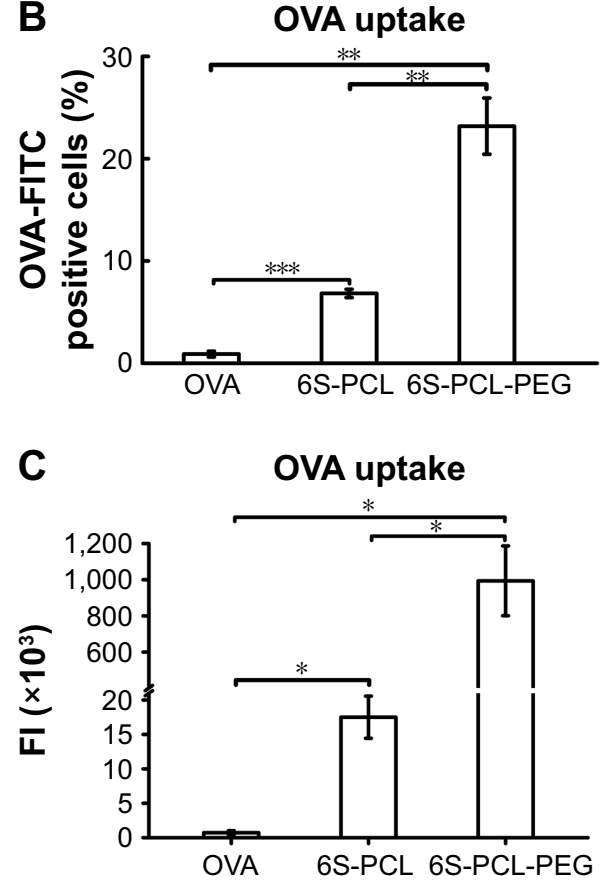

Figure 6 Cellular uptake of nanoparticles by NIH-3T3 cells. (A) NIH-3T3 cells were incubated with OVA-FITC (green) and OVA-FITC-loaded NPs for 3 h; the nucleus was labeled with DAPI (blue). The uptake of NPs was observed by confocal microscopy. (B) Percentage of OVA-FITC-positive cells. (C) Total FI of OVA-FITC; Total FI=\% of positive cells $\times$ Mean fluorescence intensity. Bars are mean $\pm S D(n=3)$. The statistical significance of differences were analyzed using Student's $t$-test: $* p<0.05$, $* * p<0.0$ I, $* * * p<0.001$.

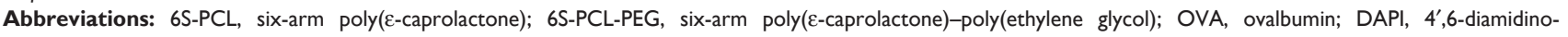
2-phenylindole; BF, bright field; FITC, fluorescein isothiocyanate; Fl, fluorescence intensity.

potential application as protein sustained-release delivery systems.

\section{Acknowledgments}

The authors are grateful for the financial support from the National Natural Science Funds of China (31771097, 31600743), Tianjin Research Program of Application Foundation and Advanced Technology (17JCZDJC37400, 16JCQNJC13900), CAMS Innovation Fund for Medical Sciences (2017-I2M-1-016), and Tianjin Innovation and Promotion Plan Key Innovation Team of Immunoreactive Biomaterials.

\section{Disclosure}

The authors report no conflicts of interest in this work.

\section{References}

1. Herrero EP, Alonso MJ, Csaba N. Polymer-based oral peptide nanomedicines. Ther Deliv. 2012;3(5):657-668.

2. Vila A, Sánchez A, Tobio M, Calvo P, Alonso MJ. Design of biodegradable particles for protein delivery. J Control Release. 2002;78(1-3): $15-24$.

3. Van Tomme SR, Hennink WE. Biodegradable dextran hydrogels for protein delivery applications. Expert Rev Med Devices. 2007;4(2): 147-164.

4. Lee KY, Yuk SH. Polymeric protein delivery systems. Prog Polymer Sci. 2007;32(7):669-697.
5. van de Weert M, Hennink WE, Jiskoot W. Protein instability in poly(lactic-co-glycolic acid) microparticles. Pharm Res. 2000;17(10): $1159-1167$.

6. Zhang N, Li J, Jiang W, et al. Effective protection and controlled release of insulin by cationic beta-cyclodextrin polymers from alginate/chitosan nanoparticles. Int J Pharm. 2010;393(1-2):212-218.

7. Garcia-Fuentes M, Prego C, Torres D, Alonso MJ. A comparative study of the potential of solid triglyceride nanostructures coated with chitosan or poly(ethylene glycol) as carriers for oral calcitonin delivery. Eur $J$ Pharm Sci. 2005;25(1):133-143.

8. Liu G, Ma SS, Cheng R, Meng F, Liu H, Zhong Z. The highly efficient delivery of exogenous proteins into cells mediated by biodegradable chimaeric polymersomes. Biomaterials. 2010;31(29):7575-7585.

9. Gutierro I, Hernández RM, Igartua M, Gascón AR, Pedraz JL. Size dependent immune response after subcutaneous, oral and intranasal administration of BSA loaded nanospheres. Vaccine. 2002;21(1): $67-77$.

10. Saito N, Usui Y, Aoki K, et al. Carbon nanotubes: biomaterial applications. Chem Soc Rev. 2009;38(7):1897-1903.

11. Malmsten M. Inorganic nanomaterials as delivery systems for proteins, peptides, DNA, and siRNA. Curr Opin Colloid Interface Sci. 2013; 18(5):468-480.

12. Al-Remawi M, Elsayed A, Maghrabi I, Hamaidi M, Jaber N. Chitosan/ lecithin liposomal nanovesicles as an oral insulin delivery system. Pharm Dev Technol. 2017;22(3):390-398.

13. Peng Q, Zhang ZR, Gong T, Chen GQ, Sun X. A rapid-acting, longacting insulin formulation based on a phospholipid complex loaded PHBHHx nanoparticles. Biomaterials. 2012;33(5):1583-1588.

14. Xie SY, Wang SL, Zhao BK, Han C, Wang M, Zhou WZ. Effect of PLGA as a polymeric emulsifier on preparation of hydrophilic protein-loaded solid lipid nanoparticles. Colloids Surf B Biointerfaces. 2008;67(2):199-204. 
15. Fang F, Gong CY, Dong PW, et al. Acute toxicity evaluation of in situ gel-forming controlled drug delivery system based on biodegradable poly(epsilon-caprolactone)-poly(ethylene glycol)-poly(epsiloncaprolactone) copolymer. Biomed Mater. 2009;4(2):025002.

16. Gong CY, Shi S, Dong PW, et al. Biodegradable in situ gel-forming controlled drug delivery system based on thermosensitive PCL-PEGPCL hydrogel: part 1 - Synthesis, characterization, and acute toxicity evaluation. J Pharm Sci. 2009;98(12):4684-4694.

17. Khodaverdi E, Akbari A, Tekie FS, Mohajeri SA, Zohuri G, Hadizadeh F. Sustained delivery of amphotericin B and vancomycin hydrochloride by an injectable thermogelling tri-block copolymer. PDA J Pharm Sci Technol. 2013;67(2):135-145.

18. Yoo HS, Park TG. Biodegradable polymeric micelles composed of doxorubicin conjugated PLGA-PEG block copolymer. J Control Release. 2001;70(1-2):63-70.

19. Wei X, Gong C, Gou M, et al. Biodegradable poly(epsilon-caprolactone)poly(ethylene glycol) copolymers as drug delivery system. Int J Pharm. 2009;381(1):1-18.

20. Gou M, Zheng L, Peng X, et al. Poly(epsilon-caprolactone)-poly(ethylene glycol)-poly(epsilon-caprolactone) (PCL-PEG-PCL) nanoparticles for honokiol delivery in vitro. Int J Pharm. 2009;375(1-2):170-176.

21. Zhou S, Deng X, Yang H. Biodegradable poly( $\varepsilon$-caprolactone)poly(ethylene glycol) block copolymers: characterization and their use as drug carriers for a controlled delivery system. Biomaterials. 2003; 24(20):3563-3570.

22. Harris JM, Chess RB. Effect of pegylation on pharmaceuticals. Nat Rev Drug Discov. 2003;2(3):214-221.

23. De Koker S, Cui J, Vanparijs N, et al. Engineering Polymer Hydrogel Nanoparticles for Lymph Node-Targeted Delivery. Angew Chem Int Ed Engl. 2016;55(4):1334-1339.

24. Papi M, Caputo D, Palmieri V, et al. Clinically approved PEGylated nanoparticles are covered by a protein corona that boosts the uptake by cancer cells. Nanoscale. 2017;9(29):10327-10334.

25. Chen Y, Yang Z, Liu C, et al. Synthesis, characterization, and evaluation of paclitaxel loaded in six-arm star-shaped poly(lactic-co-glycolic acid). Int J Nanomedicine. 2013;8:4315-4326.

26. Zeng X, Tao W, Mei L, Huang L, Tan C, Feng SS. Cholic acidfunctionalized nanoparticles of star-shaped PLGA-vitamin E TPGS copolymer for docetaxel delivery to cervical cancer. Biomaterials. 2013; 34(25):6058-6067.

27. Zhu J, Zhou Z, Yang C, Kong D, Wan Y, Wang Z. Folate-conjugated amphiphilic star-shaped block copolymers as targeted nanocarriers. J Biomed Mater Res A. 2011;97(4):498-508.

28. Poree DE, Giles MD, Lawson LB, He J, Grayson SM. Synthesis of amphiphilic star block copolymers and their evaluation as transdermal carriers. Biomacromolecules. 2011;12(4):898-906.

29. Lang M, Chu CC. Functionalized multiarm poly( $\in$-caprolactone $)$ s: Synthesis, structure analysis, and network formation. J Appl Polym Sci. 2010;86(9):2296-2306.

30. Ma G, Zhang C, Zhang L, et al. Doxorubicin-loaded micelles based on multiarm star-shaped PLGA-PEG block copolymers: influence of arm numbers on drug delivery. J Mater Sci Mater Med. 2016;27(1):17.

31. Zhu X, Liu C, Duan J, et al. Synthesis of three-arm block copolymer poly(lactic-co-glycolic acid)-poly(ethylene glycol) with oxalyl chloride and its application in hydrophobic drug delivery. Int J Nanomedicine. 2016;11:6065-6077.

32. Yang J, Zeng $Y$, Zhang C, et al. The prevention of restenosis in vivo with a VEGF gene and paclitaxel co-eluting stent. Biomaterials. 2013; 34(6):1635-1643.

33. Agrahari V, Agrahari V, Hung WT, Christenson LK, Mitra AK. Composite Nanoformulation Therapeutics for Long-Term Ocular Delivery of Macromolecules. Mol Pharm. 2016;13(9):2912-2922.

34. Liu Q, Chen X, Jia J, et al. pH-Responsive Poly(D,L-lactic-co-glycolic acid) Nanoparticles with Rapid Antigen Release Behavior Promote Immune Response. ACS Nano. 2015;9(5):4925-4938.
35. Luo Z, Li P, Deng J, et al. Cationic polypeptide micelle-based antigen delivery system: a simple and robust adjuvant to improve vaccine efficacy. J Control Release. 2013;170(2):259-267.

36. Yoon JJ, Chung HJ, Lee HJ, Park TG. Heparin-immobilized biodegradable scaffolds for local and sustained release of angiogenic growth factor. J Biomed Mater Res A. 2006;79(4):934-942.

37. Mirza S, Hossain M, Mathews C, et al. Type 2-diabetes is associated with elevated levels of TNF-alpha, IL-6 and adiponectin and low levels of leptin in a population of Mexican Americans: a cross-sectional study. Cytokine. 2012;57(1):136-142.

38. He C, Hu Y, Yin L, Tang C, Yin C. Effects of particle size and surface charge on cellular uptake and biodistribution of polymeric nanoparticles. Biomaterials. 2010;31(13):3657-3666.

39. Alexis F, Pridgen E, Molnar LK, Farokhzad OC. Factors affecting the clearance and biodistribution of polymeric nanoparticles. Mol Pharm. 2008;5(4):505-515.

40. Yuan F, Dellian M, Fukumura D, et al. Vascular permeability in a human tumor xenograft: molecular size dependence and cutoff size. Cancer Res. 1995;55(17):3752-3756.

41. Lee E, Kim S, Seong K, et al. A biodegradable and biocompatible drug-delivery system based on polyoxalate microparticles. J Biomat Sci Polym Ed. 2011;22(13):1683-1694.

42. Win KY, Feng SS. Effects of particle size and surface coating on cellular uptake of polymeric nanoparticles for oral delivery of anticancer drugs. Biomaterials. 2005;26(15):2713-2722.

43. Monfardini C, Veronese FM. Stabilization of substances in circulation. Bioconjug Chem. 1998;9(4):418-450.

44. Lee KD, Nir S, Papahadjopoulos D. Quantitative analysis of liposomecell interactions in vitro: rate constants of binding and endocytosis with suspension and adherent J774 cells and human monocytes. Biochemistry. 1993;32(3):889-899.

45. Xiao K, Li Y, Luo J, et al. The effect of surface charge on in vivo biodistribution of PEG-oligocholic acid based micellar nanoparticles. Biomaterials. 2011;32(13):3435-3446.

46. Awasthi VD, Garcia D, Goins BA, Phillips WT. Circulation and biodistribution profiles of long-circulating PEG-liposomes of various sizes in rabbits. Int J Pharm. 2003;253(1-2):121-132.

47. Lin WJ, Juang LW, Lin CC. Stability and release performance of a series of pegylated copolymeric micelles. Pharm Res. 2003;20(4):668-673.

48. Li R, Li X, Xie L, et al. Preparation and evaluation of PEG-PCL nanoparticles for local tetradrine delivery. Int J Pharm. 2009;379(1): 158-166.

49. Chen Y, Li Y, Shen W, et al. Controlled release of liraglutide using thermogelling polymers in treatment of diabetes. Sci Rep. 2016;6:31593.

50. Hu Y, Xie J, Tong YW, Wang CH. Effect of PEG conformation and particle size on the cellular uptake efficiency of nanoparticles with the HepG2 cells. J Control Release. 2007;118(1):7-17.

51. Hsu YH, Lin CT, Yu YH, Chou YC, Liu SJ, Chan EC. Dual delivery of active antibactericidal agents and bone morphogenetic protein at sustainable high concentrations using biodegradable sheath-corestructured drug-eluting nanofibers. Int J Nanomedicine. 2016;11: 3927-3937.

52. Feczkó T, Tóth J, Gyenis J. Comparison of the preparation of PLGABSA nano- and microparticles by PVA, poloxamer and PVP. Colloids Surf A Physicochem Eng Asp. 2008;319(1-3):188-195.

53. Yang YY, Chung TS, Ng NP. Morphology, drug distribution, and in vitro release profiles of biodegradable polymeric microspheres containing protein fabricated by double-emulsion solvent extraction/evaporation method. Biomaterials. 2001;22(3):231-241.

54. Zemser M, Friedman M, Katzhendler J, Greene LL, Minsky A, Gorinstein S. Relationship between functional properties and structure of ovalbumin. J Protein Chem. 1994;13(2):261-274. 


\section{Supplementary materials}

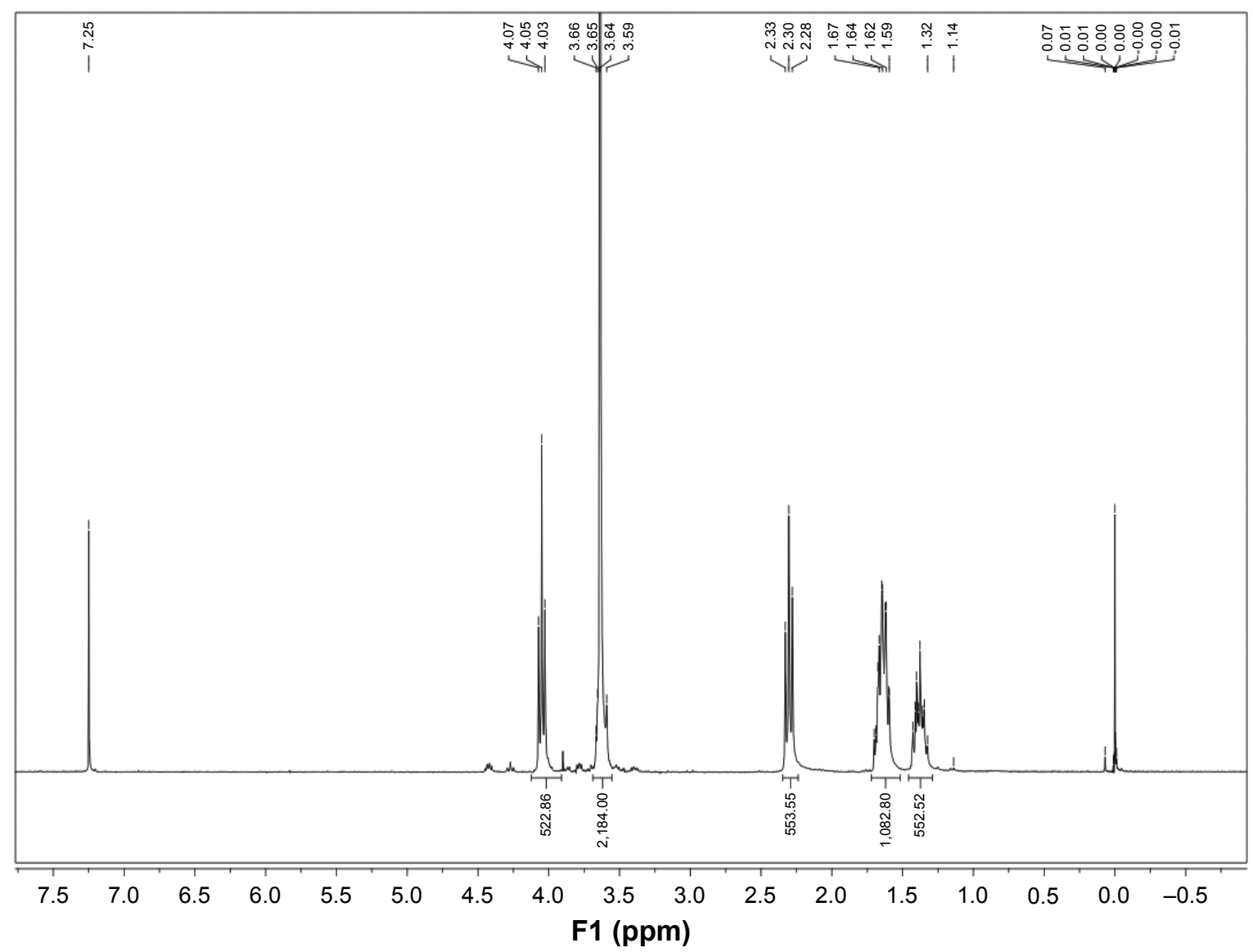

Figure SI Integration areas of NMR spectra of 6S-PCL-PEG.

Abbreviations: NMR, nuclear magnetic resonance; 6S-PCL-PEG, six-arm poly(E-caprolactone)-poly(ethylene glycol).

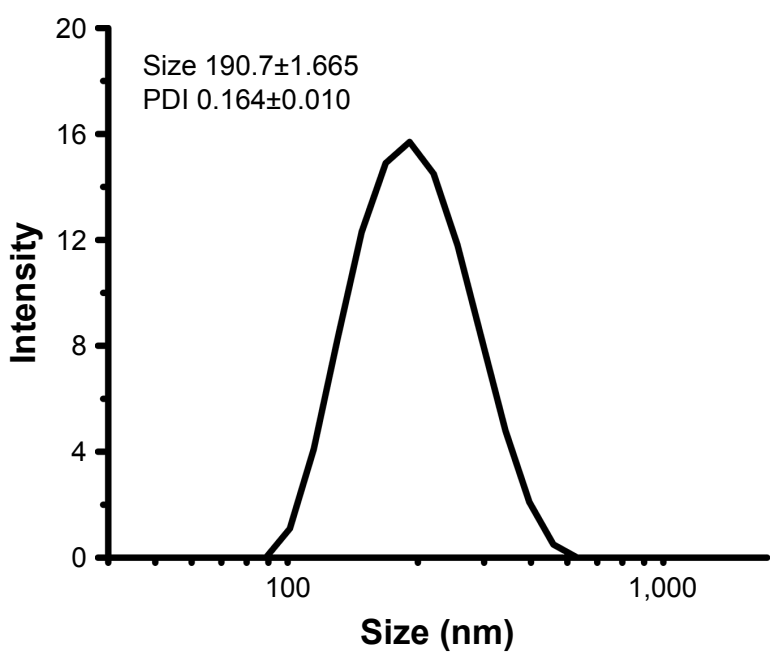

Figure S2 Size and PDI of 6S-PCL nanoparticles.

Abbreviations: PDI, polydispersity index; 6S-PCL, six-arm poly(ع-caprolactone). 

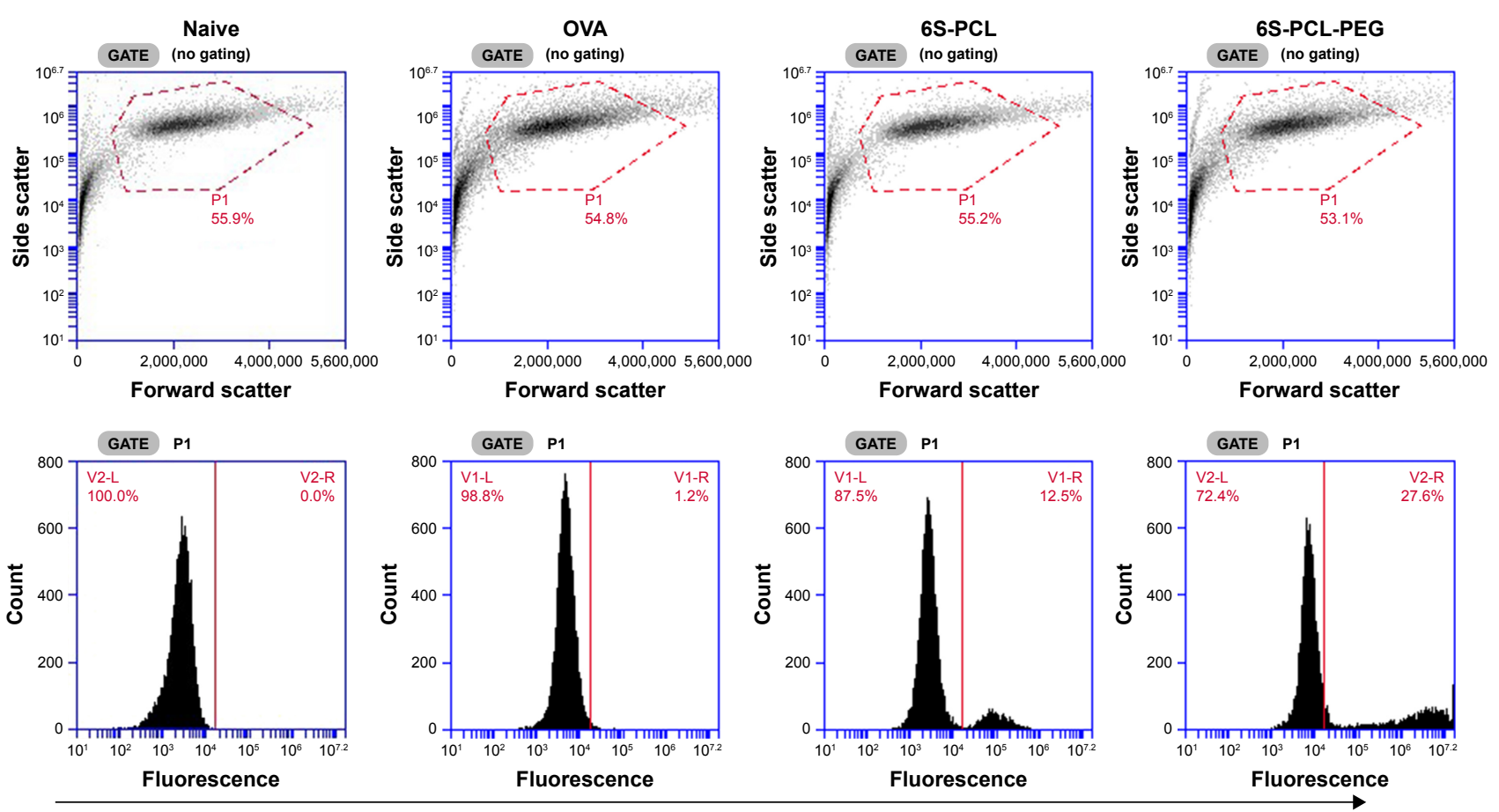

FITC

Figure S3 Representative flow plot of NPs taken up by NIH-3T3 cells.

Abbreviations: NPs, nanoparticles; OVA, ovalbumin; 6S-PCL, six-arm poly( $\varepsilon$-caprolactone); 6S-PCL-PEG, six-arm poly( $\varepsilon$-caprolactone)-poly(ethylene glycol); FITC, fluorescein isothiocyanate.

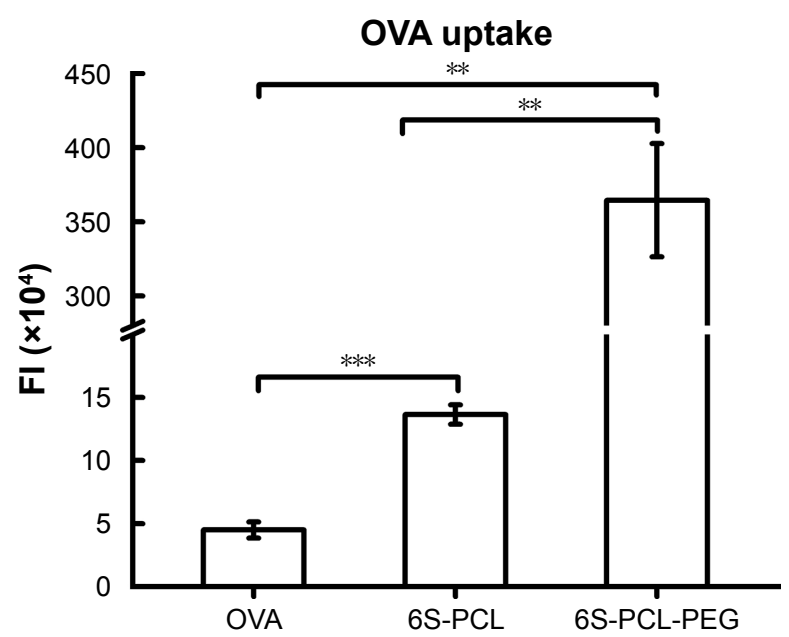

Figure S4 Mean fluorescence intensity plot of NPs taken up by NIH-3T3 cells. The statistical significance of differences were analyzed using Student's $t$-test: $* * p<0.0$ I, $* * * p<0.001$.

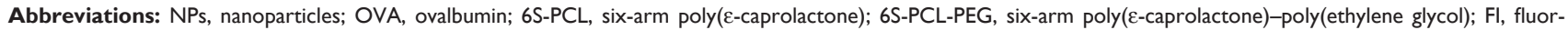
escence intensity.

\section{Publish your work in this journal}

The International Journal of Nanomedicine is an international, peerreviewed journal focusing on the application of nanotechnology in diagnostics, therapeutics, and drug delivery systems throughout the biomedical field. This journal is indexed on PubMed Central,

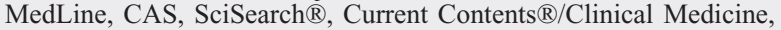

Journal Citation Reports/Science Edition, EMBase, Scopus and the Elsevier Bibliographic databases. The manuscript management system is completely online and includes a very quick and fair peer-review system, which is all easy to use. Visit http://www.dovepress.com/ testimonials.php to read real quotes from published authors. 